\title{
REFINE OF REGIONAL OCEAN TIDE MODEL USING GPS DATA
}

\author{
Fan Wang ${ }^{1}$, Peng Zhang ${ }^{1}$, Zhanyi Sun ${ }^{1}$, Zhihao Jiang ${ }^{1}$, Qinglan Zhang ${ }^{1}$ \\ ${ }^{1} 28$ Lianhuachi West Road, Haidian District, Beijing 100830, China - (wangfan, pzhang, szy, zhjiang, qlzhang)@nsdi.gov.cn
}

Commission VI, WG VI/4

KEY WORDS: GPS, OCEAN TIDE MODEL, TIME SERIES, SPECTRAL INVERSION, PPP

\begin{abstract}
:
Due to lack of regional data constraints, all global ocean tide models are not accuracy enough in offshore areas around China, also the displacements predicted by different models are not consistency. The ocean tide loading effects have become a major source of error in the high precision GPS positioning. It is important for high precision GPS applications to build an appropriate regional ocean tide model. We first process the four offshore GPS tracking station's observation data which located in Guangdong province of China by using PPP aproach to get the time series. Then use the spectral inversion method to acquire eigenvalues of the Ocean Tidal Loading. We get the estimated value of not only 12hour period tide wave (M2, S2, N2, K2) but also 24hour period tide wave (O1, K1, P1, Q1) which has not been got in presious studies. The contrast test shows that GPS estimation value of M2, K1 is consistent with the result of five famous glocal ocean load tide models, but S2, N2, K2, O1, P1, Q1 is obviously larger.
\end{abstract}

\section{INTRODUCTION}

With the improvement of positioning accuracy, GPS has been used in many researches such as current crustal movement monitoring and continental dynamics. GPS is capable to reveal detailed crustal deformation with a high spatial and temporal resolution (Hirahara, 2000). The tidal forces exerted on the Earth by the sun and the moon cause cyclical fluctuations in the sea level relative to the average sea level. The elastic response of the solid earth to the redistribution of seawater mass caused by sea tides is often called the tidal load effect. In the offshore areas, the distortion caused by the tide loading effect can reach several centimeters (Yuan et al., 2010). Therefore, the impact of ocean tidal load must be taken into account in high precision geodetic research. Corrections of ocean tide load displacements are usually obtained by discrete convolution integrals of the ocean tide model and the Green's function based on the earth model (Farrell, 1972). Therefore, the accuracy of ocean tide load corrections depends mainly on the resolution and accuracy of the ocean tide model. Penna et al. (Penna et al., 2008) used the $\mathrm{M}_{2}$ tidal wave as an example to quantitatively evaluate the accuracy of the correction of the ocean tide load displacement model. The results show that the differences in ocean load displacement calculated by different models are 1 to $2 \mathrm{~mm}$ in the coastal area, for the IGS stations, the different root-meansquare error of the load displacement obtained by the tide model can reach $3 \mathrm{~mm}$ in the vertical direction and $8 \mathrm{~mm}$ in some coastal areas. At the same time, the deviation of the tidal wave in the tide model will evolve into a false periodic signal confounded in the time series (Penna and Stewart, 2003), thus misleading the study of real periodic signals. An accurate tide model can improve the accuracy of GPS positioning, similarly, the precision GPS measurements can also contribute to refine the ocean model, which is a positive feedback process. It can be seen that improving the accuracy of ocean tide load models, especially in offshore areas, is of great practical significance for improving GPS accuracy and reliability.

Many previously studies have recognized the significance of ocean tide loading effects in GPS. Khan and Tscherning (Khan and Tscherning, 2001) published results of vertical deformation due to the semi-diurnal constituents of ocean tide loading using DGPS in Alaska. Vey et al. (Vey et al ., 2002) presented results from a GPS experiment studying crustal displacements caused by ocean loading effects and their impact on zenith tropospheric delay estimates in France. Greaves et al. (Greaves et al .,2008) first conducted related research and they used the British GPS observation data to study the tide load, S2 and M2 results obtained from current GPS data and the FES99 model The difference is only 5\%. Vergnolle (Vergnolle et al.,2008) carried harmonic analysis by useing 14 GPS stations which located in northwestern france, found that the tide load correction differences between GPS inversion results and FES2004 model are $2 \sim 7 \mathrm{~mm}$, the amplitude difference of some tidal wave components is only sub-millimeter; Ito et al. (Ito et al.,2009) use Japan's dense GPS array and ultra guided gravimeter data extraction M2, found that the initial phase and amplitude given by global tide model and GPS observation are different.Yuan et al. ( Yuan et al.,2010) used several years of GPS data in Hong Kong calculating the eight major ocean tide components.

A large number of continuous GPS tracking stations which located in the offshore area of China have been built up under many major projects, this provides us with an opportunity and possibility to refine Chinese local ocean tide model. We first refine the regional ocean tide model using GPS data. After that, analysis the presion of 'new' ocean tide model.

\section{CONSTRUCT OCEAN TIDE MODEL USING GPS STATION}

\subsection{GPS data processing}

In order to deduce the displacements caused by the ocean tide loading effect, we selected 4 permanent GPS trcaking stations (GDSG, GDZH, GDST and GDZJ )located in Guangdong province of China. The GPS analysis software Bernese ( Hugentobler., 2007) has been employed to analyze the GPS data. The data processing started with automatic editing of the GPS data. This included the elimination of bad data points, 
cycle slip detection, and repairs. The used processing strategy was compliant with IGS standards.We performed carrier-phase analysis and used precise IGS ephemerides. Solid earth tide and pole tide corrections were applied. Phase ambiguities were solved and fixed to integer values. The Neill tropospheric zenith delay model and the Neill mapping function were applied and hourly solutions of station position were estimated. We use PPP aproach to process the GPS data that span (2015-2016), the data were sepearted to 2 hour a session. So we get the coordinate time series, which are shown in Fig 1-Fig 4.

\subsection{Spectral estimation and interpolation}

Then used CLEAN (Bsisch and Bokelmann, 1999) algorithm to estimate every tidal wave, this algorithm is a powerful tool for the spectral estimation and interpolation of any finite regularly sampled time series with data gaps. The basic concept of the CLEAN algorithm is to deduce the amplitude of a cosinusodial and remove its contribution to dirty spectrum including all sidelobes (Baisch and Bokelmann, 1999). Values for amplitude A and phase $\Phi$ of signal frequency $v$ are obtained from least squares estimation by solving Eq. (1). For the discrete times $t=$ $\mathrm{t} 1, \mathrm{t} 2, \ldots, \mathrm{tn}$ the vertical displacement $\psi(\mathrm{t})$ by ocean tide loading derived from GPS becomes:

$$
\psi(t)=A \cos (\varnothing) \cos (2 \pi v t)-A \sin (\varnothing) \sin (2 \pi v t)+\eta(t)
$$

where $\mathrm{A}$ is the unknown amplitude, $\Phi$ the unknown phase, $2 \pi$ $v$ the test frequency, and $\eta(t)$ is the measure of the 'noise' which includes any process different from the signal. We can write the linear equation system of Eq. (1) based upon the least square solution as follows:

$$
\left[\begin{array}{c}
\varphi(\mathrm{t}) \\
\varphi(\mathrm{t}+\Delta \mathrm{t}) \\
\vdots
\end{array}\right]=\mathrm{Gm}+\vec{\eta}
$$

Where,

$$
\begin{gathered}
\mathrm{G}=\left[\begin{array}{cc}
\cos (2 \pi v(\mathrm{t})) & \sin (2 \pi v(\mathrm{t})) \\
\cos (2 \pi v(\mathrm{t})+\Delta \mathrm{t}) & \sin (2 \pi v(\mathrm{t})+\Delta \mathrm{t}) \\
\cos (2 \pi v(\mathrm{t})+2 \Delta \mathrm{t}) & \sin (2 \pi v(\mathrm{t})+2 \Delta \mathrm{t}) \\
\vdots \\
\overrightarrow{\mathrm{m}}=\left[\begin{array}{c}
\mathrm{A} \cos (\varphi) \\
-\operatorname{Asin}(\varphi)
\end{array}\right]
\end{array}\right.
\end{gathered}
$$

The estimated results are shown in Fig 2 and Table 1. It is clear that we get the estimated value of both of $\sim 12$ hour period tide wave (M2, S2, N2, K2) and 24 hour period tide wave (O1, K1, P1, Q1). The results of previous studies (Khan and Tscherning, 2001, Hong-Sic et al., 2007) show only the semidiurnal waves. The effort is mainly due to the reason that we have taken longer observation data and more accurate physical models, and obtained higher accuracy time series. Observation time span impact the estimated result a lot, the stations (such as GDZJ) with shorter obserevation span couldn't get a convergence estimation results.
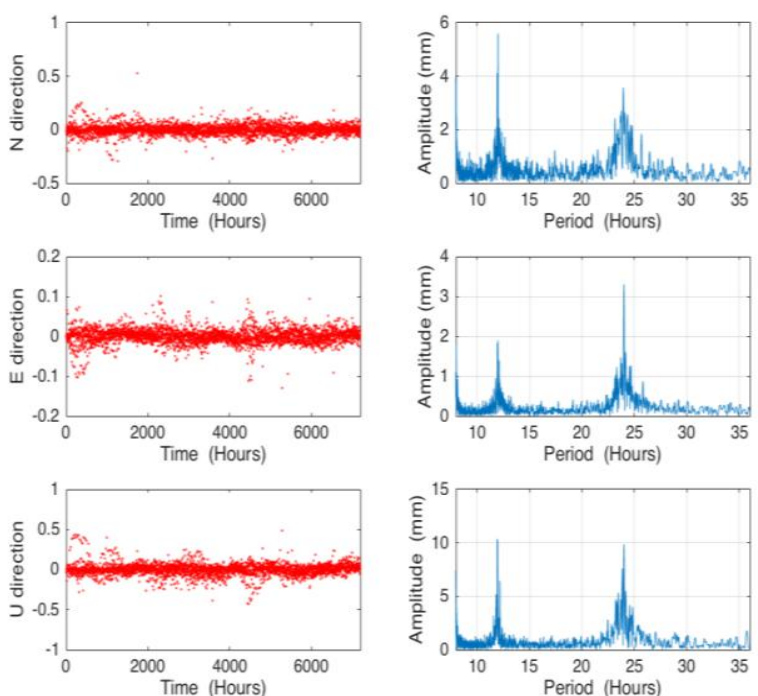

Figure 1. Coordinate time series (left) and spectrum analysis (right) of GDSG station
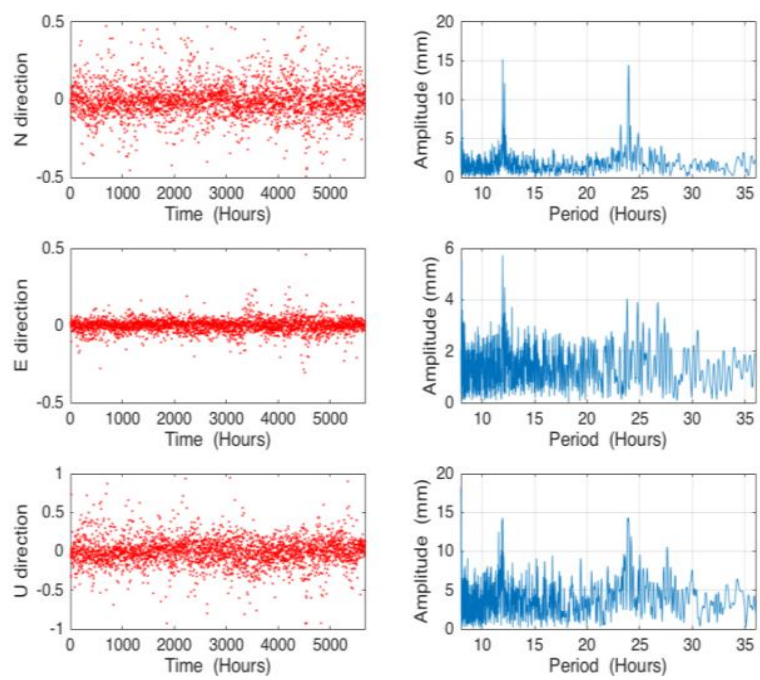

Figure 2. Coordinate time series (left) and spectrum analysis (right) of GDZH station
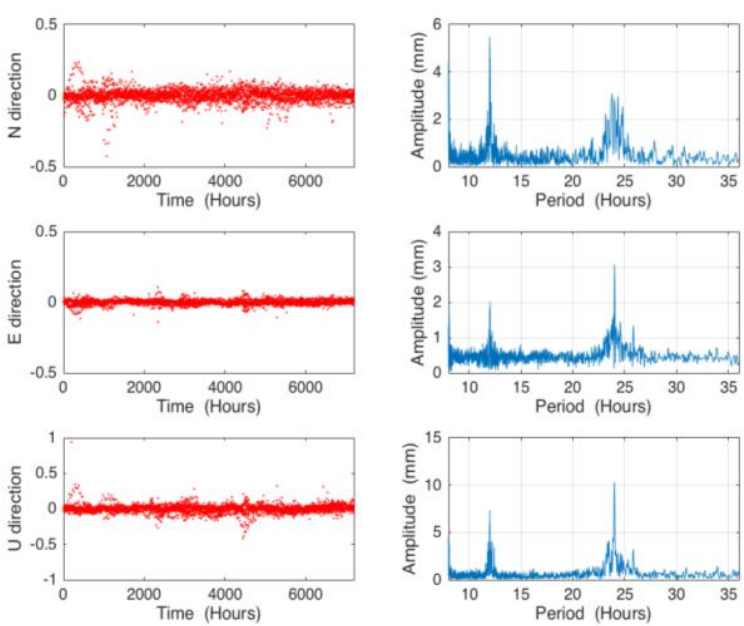

Figure 3. Coordinate time series (left) and spectrum analysis (right) of GDST station 

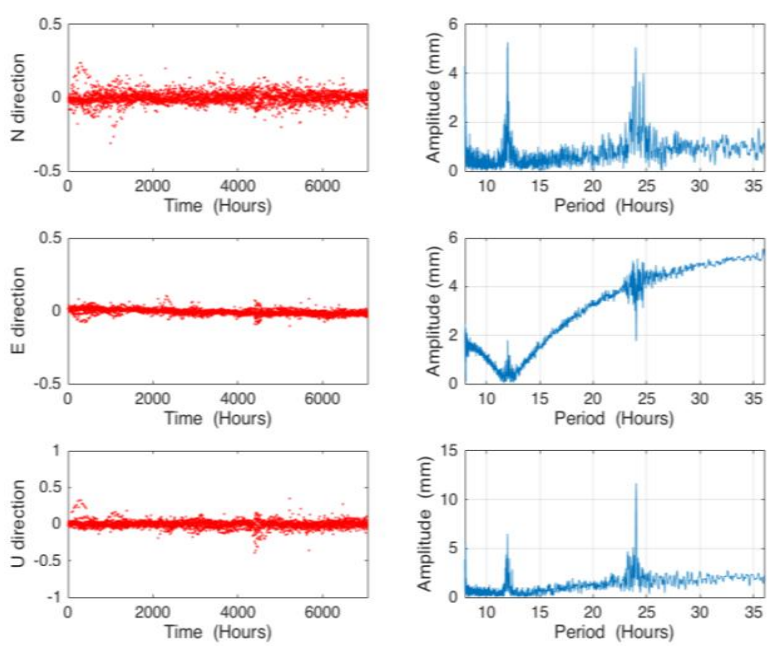

Fig 4. Coordinate time series (left) and spectrum analysis (right) of GDZJ station

\section{PRESION ANALYSIS OF THE NEW OCEAN TIDE MODEL}

In order to evaluate the accuracy of the new ocean load tide model, SPOTL (Agnew, 1997) was used to calculate the displacement caused by ocean tide load for each station. In this paper, the latest five (EOT08a, FES2004, TPXO7.1, GOT4.7 and NAO99b) models were used for comparison. The comparison which is shown in Table 1 revealed that, GPS estimation value of M2, K1 is consistent with the result of five models, but S2, N2, K2, O1, P1, Q1 is obviously larger. The reason for this deviation is partly due to the inaccurate correction of ocean tidal load model, but other potential sources of error can not be ignored. It is necessary to use the global GPS station indepth study in mainland China, especially in the eastern coastal areas, it is necessary to introduce more continuous operating reference station, between the geographical proximity of base station to determine the tidal wave valuation can verify each other, but also the multipath effect is equal to the influence of station environment effect.

\section{CONCLUSIONS:}

Ocean tide loading is an important error source in the precision satellite positioning. Accurate ocean tide model can improve GPS positioning accuracy. A GPS experiment was carried out to measure the displacements generated by ocean tide loading in this paper. We processed the observation data of four GPS tracking stations by using PPP approach and get the position time series, then carried spectral estimation and interpolation of the time series in order to get the ocean load tides. The results show that GPS technology can detect submillimeter level tidal deformation, we can use GPS data refine the regional ocean load tide model which is not accurate enough because of lock of data constrainte. The model can be used to correct the inaccuracy of Chinese regional ocean tide model in the future. The new model can be applied to high accuracy GNSS data processing, gravity data processing, and sea tide compliance calculation. The continuous refinement of the model can also enable GNSS to capture weaker signals, thereby facilitating the in-depth study of earth sciences.

\section{ACKNOWLEDGEMENTS (OPTIONAL)}

This work was supported by National Natural Science Foundation of China (41304008) and (41504020).

\section{REFERENCES}

Agnew D C. SPOTL: Some programs for ocean-tide loading[J]. 2012, 96-8.

Baisch, S., Bokelmann, G.H.R., 1999. Spectral analysis with incomplete time series: an example from seismology. Comput. Geosci. 25, 739-750.

Farrell W E. Deformation of Earth by surface loads. Rev Geophys Space Phys, 1972, 10: 761—797

Greaves M, Fane C, Cruddace P, et al. National Report of Great Britain, 2003[J]. Philosophy of Science, 2008, 4(1):429-468. Hirahara, K., 2000. Local GPS tropospheric tomography. Earth Planets Space 52, 935-939.

Hugentobler U. Bernese GPS software Version 4.2[J]. Universitas Berneseis, 2007, 515(2):535.

Ito T, Okubo M, Sagiya T. High resolution mapping of Earth tide response based on GPS data in Japan[J]. Journal of Geodynamics, 2009, 48(3-5):253-259.

Khan, S.A., and C.C.Tscherning, Determination of semi-diurnal ocean tide loading constituents using GPS in Alaska, Geophys. Res. Lett.,2001:28

Penna N T, Stewart M P. Aliased tidal signatures in continuous GPS height time series, Geophysical Research Letters,2003,30

Penna N. T., M. S. Bos, T. F. Baker and H. Scherneck (2008). Assessing the accuracy of predicted ocean tide loading displacement values, Journal of Geodesy 82, 893-907

Vergnolle M, Bouin M -, Morel L, et al. GPS estimates of ocean tide loading in NW-France: determination of ocean tide loading constituents and comparison with a recent ocean tide model[J]. Geophysical Journal of the Royal Astronomical Society, 2010, 173(2):444-458.

Vey, S., Calais, E., Llubes, M., Florsch, N., Woppelmann, G., Hinderer, J., Amalvict, M., Lalancette, M.F., Simon, B., Duquenne, F., Haase, J.S., 2002. GPS measurements of ocean loading and its impact on zenith tropospheric delay estimates: a case study in Brittany, France. J. Geodesy 76, 419-427.

Yuan L G, Ding X L, Sun H P, et al. Determination of ocean tide loading displacements in Hong Kong using GPS technique. Sci China Earth Sci, 2010

Yun H S, Lee D H, Song D S. Determination of vertical displacements over the coastal area of Korea due to the ocean tide loading using GPS observations[J]. Journal of Geodynamics, 2007, 43(4-5):528-541. 


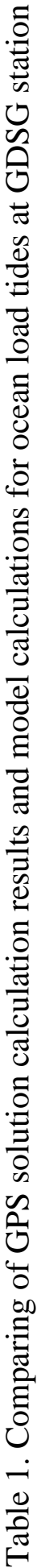

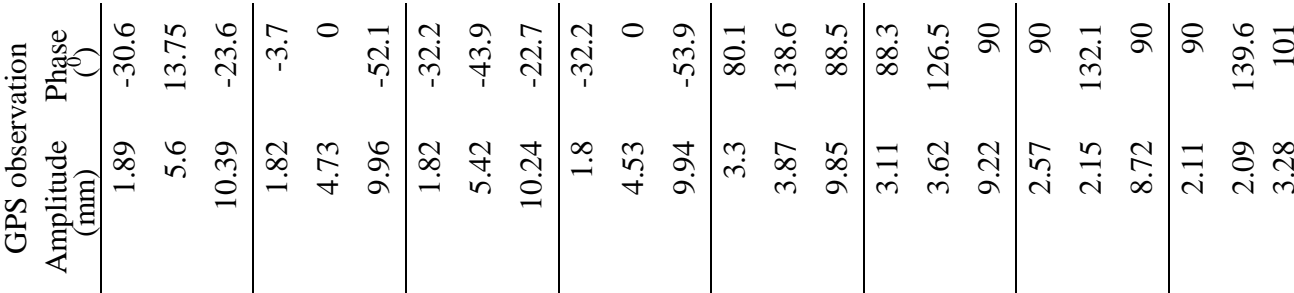

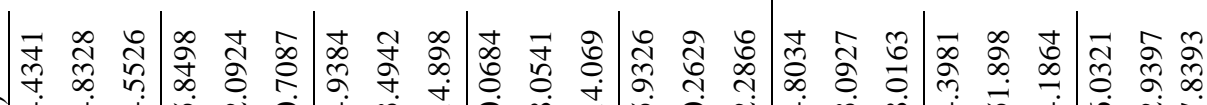

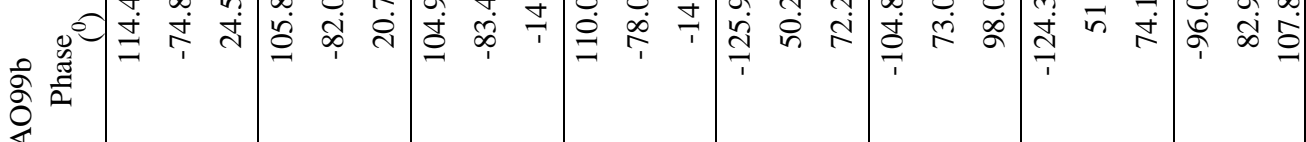

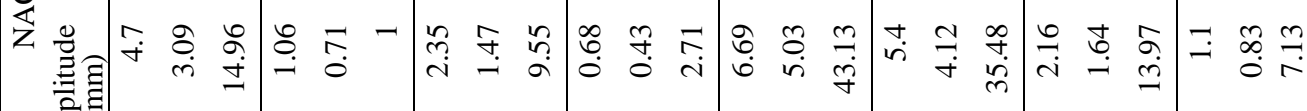

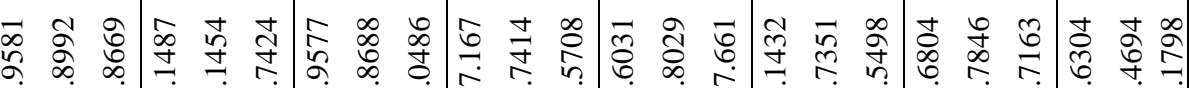

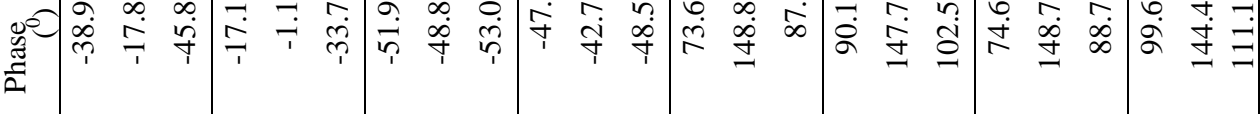

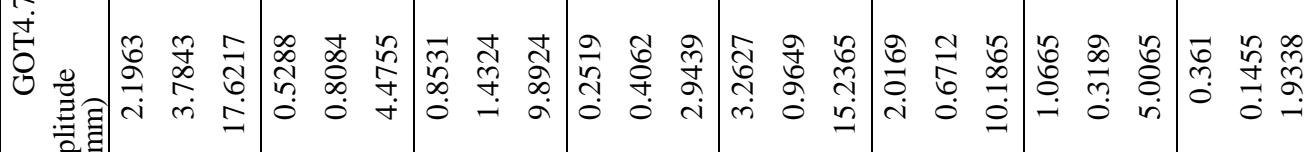
衰

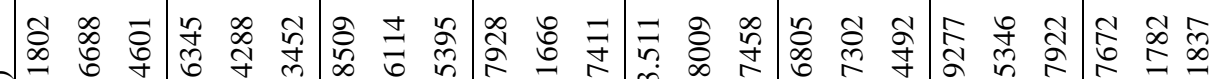

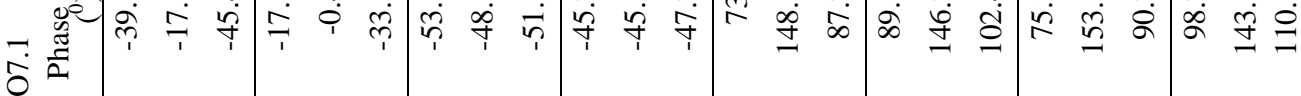

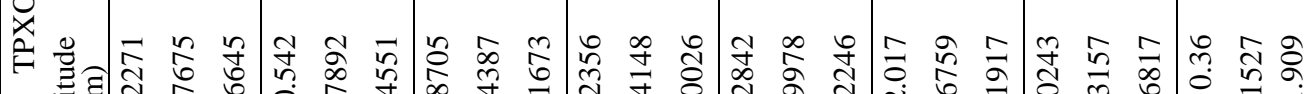
旁园

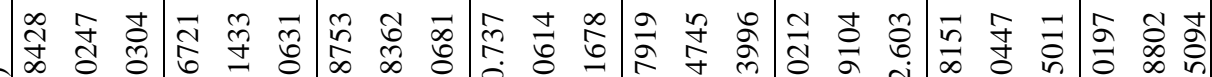

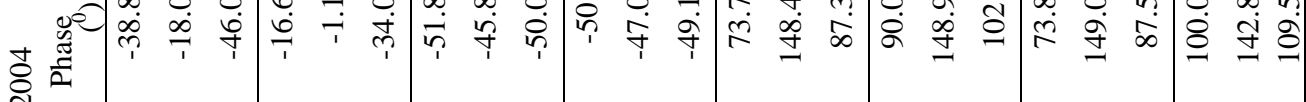

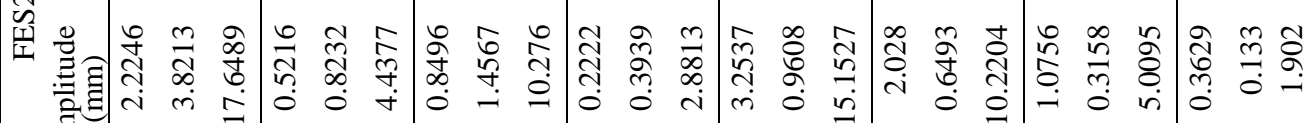

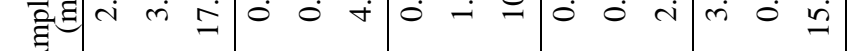
$<$

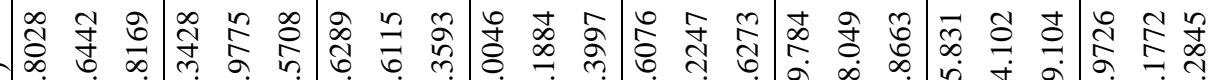
势

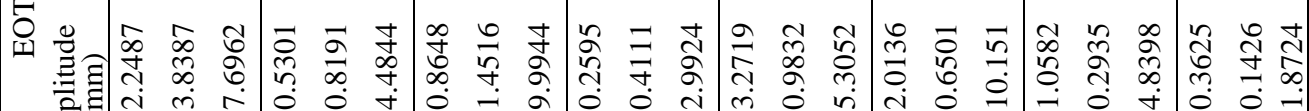
言递

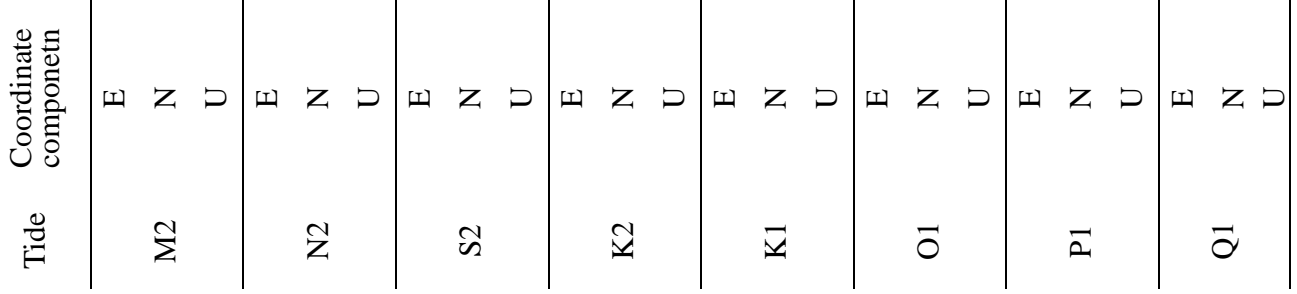

